\title{
Entrenamiento de la pliometría y propiocepción en discapacidad cognitiva, síndrome de Down y autismo*
}

\author{
Cesar Alonso Aguilar Mejía* \\ Ricardo Rodríguez Cepeda"*
}

Recibido: febrero 02 del 2020 • Aceptado: abril 22 del 2020

\section{Resumen}

El propósito de esta investigación fue contribuir en la mejora de la estabilidad postural estática unipodal (EPEU) y la capacidad de salto vertical (CSV) por medio del entrenamiento de la pliometría y propiocepción en sujetos con síndrome de Down (SD), autismo (A) y discapacidad cognitiva (DC) de la ciudad de Bogotá, Colombia, en el 2019. Como método se utilizó la valoración de la EPEU, que se ejecutó bajo el protocolo de Iowa Brace (IB), y la CSv, bajo el protocolo de Abalakov (ABK). Se realizó un entrenamiento de propiocepción y pliometría de dos meses y tres semanas (once semanas) con una frecuencia de dos sesiones semanales y una duración por sesión de dos horas. Se obtuvo como resultados una mejora significativa en la CSV $(r=0.95$, ET (Error típico) $2.81, p<0.000)$ y en la EPEU ( $\mathrm{r}=0.57$, ET $=0.60, p<0.005)$. Hubo un cambio entre el pre y postest de un $23.7 \%$ a favor del protocolo de ABK,

\footnotetext{
Artículo de investigación. Financiación propia. Semillero de investigación de entrenamiento deportivo del Areandina. Fundación Universitaria del Areandina, Bogotá, Colombia.

Citar como: Aguilar, C. y Rodríguez, C. (2020). Entrenamiento de la pliometría y propiocepción en discapacidad cognitiva, síndrome de Down y autismo. Revista de Investigación Cuerpo, Cultura y Movimiento, 10(2), 151-182. DoI: https://doi.org/10.15332/2422474x/6231

** Profesional en entrenamiento deportivo; entrenador deportivo, Fundación Universitaria del Areandina, Colombia. Correo electrónico: cesar_alonso80@hotmail.com, orCID: 0000-0001-6478-0577

*** Profesional en entrenamiento deportivo; entrenador deportivo, Fundación Universitaria del Areandina, Colombia. Correo electrónico: rrodriguez74@estudiantes.areandina.edu.co, ORCID: 0000-0002-2813-097X
} 
y un $48.4 \%$ favorable con el protocolo Iв. Se concluyó que ambos tipos de entrenamiento (pliométrico y propioceptivo) mejoran significativamente la EPEU y la CSV en sujetos con SD, A y DC, contribuyendo a la coordinación y estabilidad de gestos mecánicos cotidianos y disminución de la pérdida del equilibrio. Se recomiendan entrenamientos de fortalecimiento (en glúteos y core) y de corrección postural.

Palabras clave: Estabilidad estática unipodal, capacidad de salto vertical, entrenamiento. 


\section{Effects of Plyometrics and Proprioception Training on Cognitive Impairment, Down Syndrome, and Autism}

Abstract

The purpose of the research was to contribute to the improvement of Unipedal Postural Stability and Vertical Jump Ability through plyometrics and proprioception training in subjects with Down syndrome, autism, and cognitive impairment in Bogotá, Colombia, in 2019. The methods used were the Unipedal Postural Control Assessment (UPCA), performed under the Iowa Brace protocol, and the Vertical Jump Ability Assessment (VJAA), under the Abalakov protocol. Proprioception and plyometric training were carried out for 2 months and three weeks ( 11 weeks) with a frequency of 2 weekly sessions and a duration of 2 hours per session. As a result, a significant improvement was obtained in the VJAA $(\mathrm{r}=0.95$, SE (standard error) $2.81, \mathrm{p}<0.000)$ and in the UPCA $(\mathrm{r}=0.57, \mathrm{SE}=0.60, \mathrm{p}<0.005)$. There was a change between pretests and posttests of $23.7 \%$ in favor of the Abalakov protocol and of $48.4 \%$ in favor of the Iowa Brace protocol. Both types of training (plyometric and proprioceptive) significantly improve Unipedal Postural Control Assessment and Vertical Jump Ability Assessment in subjects with Down syndrome, autism and cognitive impairment, contributing to the coordination and stability of daily mechanical gestures and the decrease of the loss of balance. Strengthening (gluteal and core) and postural correction training are recommended.

Keywords: unipedal postural stability, vertical jump capacity, training. 


\section{Introducción}

La discapacidad cognitiva (DC), según la American Association of Intellectual Discapacites or from Development (AAIDD, 20II), es la característica y predisposición de una persona con limitaciones en cuanto a su desarrollo cognitivo y sus procesos de aprendizaje, cuyo origen haya sido previo a los 18 años de edad. Por otro lado, el autismo (A) es un síndrome que afecta el desarrollo normal e integral de los procesos neurológicos, como la dificultad de las interacciones interpersonales, una deficiencia de comunicación oral fluida y una gama sensitiva enfocada o restringida (Muñoz, 2005; Finkelstein, Nickel, Barnes y Suma 2010). Finalmente, el síndrome de Down (SD) se define como una alteración de orden genético, en la que los sujetos tienen 47 cromosomas en comparación a los 46 que normalmente se posee, produciendo anormalidades en el desarrollo cognitivo, físico y psicosocial (Laudan y Jahromi, 2008).

En la población con DC, A y SD se manifiestan problemas específicos de las habilidades motrices básicas, del control de sus funciones corporales y visuales, del escaso tono muscular y la falta de equilibrio, entre otras (Llasera, 1995; López, 2019). El desarrollo motor de cada individuo con DC, SD y A varía dependiendo de factores como el nivel cognitivo, ya que personas con un nivel leve de afectación patológica de DC, A y SD pueden llegar a tener un desarrollo normal y eficaz en su motricidad; en cambio, si la persona tiene un nivel de afectación cognitiva severa, puede presentar un menor desarrollo motriz (Alonso, 2018; Sowa y Meulenbroek, 2012), o deficiencias a nivel de percepción, atención, memoria y recreación de pensamientos (López y Sanjuan, 2002; Mendoza, 2017).

Como aspectos generales, en los sujetos con SD, A y DC se identifican problemas de carácter neuromotriz, alteraciones fisiológicas y morfológicas, y trastornos de carácter psicológico, debido a situaciones de origen genético o de desarrollo cognitivo. Esto trae como consecuencias problemas posturales: cadenas cinéticas en desbalance y asimetrías musculares, que son variables representadas a nivel de fuerza (Llasera, 1995; López y Sanjuan, 2002; Almeida et al., 2000).

De dichas características de la población nació la siguiente pregunta de investigación: ¿Cuál es el efecto de un entrenamiento pliométrico y de propiocepción sobre la estabilidad estática unipodal y la capacidad de salto vertical 
en 22 sujetos con SD, DC y A entre los 19 y 35 años de edad, miembros de la Fundación Sin Límites Enlaces para Crecer y Servir, en el 2019 de la ciudad de Bogotá-Colombia? También es importante resaltar que actualmente no hay estudios que atiendan específicamente los efectos agudos o acumulativos que genera el entrenamiento de la pliometría y propiocepción en dicha población.

De esta manera, el propósito de la investigación fue contribuir a la mejora de la estabilidad estática unipodal y capacidad de salto vertical por medio del entrenamiento de la pliometría y propiocepción en 22 sujetos con SD, DC y A entre los 19 y 35 años, miembros de la Fundación sin Límites Enlaces para Crecer y Servir, en el transcurso del 2019, de la ciudad de Bogotá-Colombia.

\section{Aspectos fisiológicos y motrices en sujetos con SD, DC y A}

Los sujetos con SD se caracterizan por poseer hipermovilidad articular y, como consecuencia de ella, se genera un alto grado de movimiento de sus articulaciones, como por ejemplo la hipermovilidad de la rótula y la poca estabilización de la cabeza a nivel cervical - debido a una laxitud ligamentaria mayor en las cervicales- (Eberhard y Steiner, 1997). También se debe considerar el fácil desarrollo de síndromes metabólicos, sobre todo la obesidad y el sobrepeso (Villa y García, 2005). La obesidad y el sobrepeso son comunes en los sujetos con SD, causando un estrés articular debido a cargas de compresión que deben soportar dichas estructuras, como las articulaciones coxofemorales, astrágalotibiales o de la rodilla (Eberhard y Steiner, 1997). También se recomienda evitar las contracciones isométricas en dicha población, ya que pueden aumentar drásticamente la presión arterial (Block et al., 1999; McConachie et al., 2015).

La población con SD tiene una higiene postural inadecuada. Por esa razón, autores como Villa y García (2005) recomiendan planes de entrenamiento enfocados a la mejora progresiva del equilibrio, mediante el control de simetrías y balances (en cuanto a la fuerza muscular). Por otro lado, la hipotonía es una patología de orden etario y mucho más relevante en dicha población con SD, que trae como consecuencia la hipermovilidad y dificultad para ejecutar acciones motrices explosivas o el entrenamiento de la fuerza máxima (Villa y García, 2005).

La DC tiene orígenes multifactoriales como el genético, las infecciones virales, la desnutrición o aspectos extrínsecos como el medio ambiente 
(Tajima et al., 2009; Mormino et al., 2014). La DC se caracteriza por retrasos del desarrollo motriz, siendo sus gestos biomecánicos muy ineficientes. Esto significa que su desarrollo físico coordinativo y condicional tienen una deficiencia evolutiva a causa de un mal funcionamiento nervioso y cognitivo, que no permite el desarrollo motriz adecuado del sujeto con DC (Tajima et al., 2009).

Los sujetos con a poseen una gama sensitiva o espectro sensorial limitado. Por lo tanto, sus capacidades de comunicación y de desarrollo social son ineficientes. Flood, Korol, Ekselius, Birnir y Jin (2019) nos indica que esto se debe a la dificultad de procesar con calidad las aferencias sensoriales y procesar las eferencias o respuestas óptimas a nivel cognitivo y motriz. A largo plazo, su desarrollo reducido, ya sea motriz o cognitivo, causa patologías o afecciones como lesiones osteomusculares y síndromes metabólicos (Flood et al., 2016; Bauman y Kemper, 1985). Una ventaja de su gama sensitiva reducida es la facilidad de realizar tareas simples que requieran altos focos atencionales (Hervás, 2016).

La condición motriz depende del nivel cognitivo que presenta la persona; es decir, si la persona tiene un mayor déficit cognitivo se puede decir que su capacidad motriz es menor, y con esto se evidencia en la población con SD, A y DC un inadecuado esquema corporal, una mala orientación, el poco equilibrio, la respiración superficial, una tensión muscular alta, la poca amplitud de movimiento y un nivel de condición física pobre (López y Sanjuan, 2002; Acosta, 2015). Un sujeto con SD, A y DC requiere una mayor supervisión a la hora de realizar alguna actividad, ya que ciertas circunstancias o eventos suelen dispersarlo. Debido a su déficit de atención y a sus cambios de carácter, su capacidad de relacionarse y de entrega a cosas nuevas es limitada y variable (López y Sanjuan, 2002; Acosta, 2015).

Los sujetos con SD, DC y A, durante el desarrollo se sus vidas, poseen una mayor probabilidad de tener Alzheimer o patologías de orden nervioso, debido a que sus neuronas y células Glía no cumplen su papel funcional con la misma calidad que en un sujeto sin SD, DC y A, llegando a producir fácilmente placas neuríticas (López et al., 2017; Mendoza, 2017; López, 2019). En cuanto al sistema orgánico, se evidencia ciertas deficiencias como la hiperactividad a nivel cardiovascular y deficiencias del sistema respiratorio, así como alteraciones metabólicas y osteomusculares (López y Sanjuan, 2002). La buena psicomotricidad es un aspecto primordial para el desarrollo personal (Berruezo, 1996) y, para esto, se requiere un afecto emocional por parte de 
la familia, lo que mejora el desarrollo motriz y cognitivo (Chávez y Delgado, 2009; Sánchez, 1986; Fernández, 2000; Hoz, 1996; Wehmeyer, Kelchner y Richards, 1996; Cossio, Vidal, Lagos y Gómez, 2015).

\section{Importancia de la medición y control del salto y estabilidad postural estática}

Antes de abarcar la importancia del salto en la población con SD, DC y A, primero hay que comprender su significado. Según Villa y García (2005), el salto es la capacidad de ejecutar de forma mecánica un trabajo excéntrico y concéntrico, donde se manifiesta la elasticidad articular, cuya principal manifestación metabólica es la potencia anaeróbica o glucolítica a nivel del citosol (Weineck, 2005). Según varios artículos, la medición de la potencia anaeróbica o glucolítica en la ejecución de los saltos traen como beneficio el control y conocimiento de la fuerza que es útil, es decir, que esa transferencia en la ejecución de movimientos sean funcionales para la vida cotidiana, como al esquivar un objeto que nos pudiera hacer daño, subir peldaños altos, poder cambiar rápidamente de dirección o en su aplicación en deportes como natación, levantamiento de pesas, gimnasia, fútbol, deportes de combate, entre muchos otros (Torres, Farías, Espoz y Álvarez, 2019; Giagazoglou, Kokaridas, Sidiropoulou, Patsiaouras y Karra, 2013; González et al, 2009).

Es importante resaltar que, para llegar al desarrollo de la fuerza muscular y su manifestación en la potencia anaeróbica (salto), se debe seguir un procedimiento de adaptación y asimilación integral, tanto de las cargas como de ciertos patrones motrices y posturales. El procedimiento lógico y organizado consiste en (1) contribuir a mejorar la orientación espacial; (2) corregir ciertos malos hábitos posturales; (3) trabajar el equilibrio estático; (4) mejorar la percepción externa e interna del sujeto y (5) trabajar la coordinación corporal, para lograr finalmente la mejor transferencia al entrenamiento o evaluación periódica de la potencia anaeróbica manifestada en el salto (Weineck, 2005; Hans y Hans, 2005).

Estudios anteriores sobre pliometría realizados a poblaciones con SD, DC y A demuestran que el trabajo con estos tipos de entrenamiento mejora la capacidad cardiorrespiratoria, la fuerza explosiva en miembros inferiores, la capacidad de coordinar músculos agonistas y antagonistas, al igual que 
una mejora en la estabilidad postural (González et ál., 2014; Acosta et al., 2019; Weuve, 2004). Un estudio de González et al. (2014), realizado sobre 27 jóvenes entre los 10 y 19 años con el propósito de saber si un entrenamiento de 21 semanas en forma de circuito, donde se integraban métodos pliométricos en su mayoría, mejoraba considerablemente la capacidad cardiorrespiratoria, arrojó como resultado que efectivamente los participantes mejoraron su rango de capacidad cardiorrespiratoria en comparación con las tomas iniciales $(p<0,05)$. Por otro lado, la intervención realizada por Acosta et ál. (2019) a personas con DC y A arrojó una mejora en el equilibrio y la capacidad de potencia en miembros inferiores, lo que se reflejó en una corrección postural y mejora de los patrones de movimientos. Los autores implementaron un entrenamiento basado en las artes marciales, específicamente el Taekwondo, durante 15 semanas.

\section{Estabilidad postural estática}

La terapia física tiene el propósito de contribuir a la mejora constante de la movilidad articular, el equilibrio y la estabilidad postural. En personas con SD, A y DC los déficits más evidentes son la incapacidad de mantener la correcta postura, llevándolos a desórdenes posturales (en cadenas cinéticas) que les trae muchos problemas en su salud, como escoliosis, hiperlordosis, hipercifosis, presión excesiva de los ligamentos o articulaciones, diástasis recti, entre muchos otros imbalances y asimetrías (Mateer, 2003; Lang et al., 2010).

Según Hernández (2018), los entrenamientos que fortalezcan de forma neuromuscular la población con DC, SD y A tienen mejoras significativas en su estabilidad estática. Su estudio fue realizado a 13 nadadores con el propósito de determinar si un programa de entrenamiento sensorial y motriz podría contribuir a la mejora del equilibrio estático. El entrenamiento consistió en mejorar la postura y el sentido vestibular a través de ejercicios isométricos y de propiocepción, ejecutados tres veces por semana durante un mes, cuyas sesiones siempre se caracterizaron por tener un diálogo con los sujetos de forma oral y auditiva, así como un feedback al final de estas, lo que dio como resultado significativo la mejora del equilibrio estático.

Es evidente que la debilidad postural lleva a que la población con DC, SD y A realice movimientos bruscos o incluso torpes (Hernández, 2018; Almedia 
et al, 2000), debido a que ellos poseen un volumen de masa muscular bajo (hipotonía), además de su discapacidad de integrar conjuntamente y procesar todas las aferencias en el sistema nervioso central, ya que este reconoce cuáles son sus barreras y prefiere hacer movimientos seguros y torpes algunas veces (Webbers, Virji-Babul, Edwards y Lesperance, 2004).

La mejora en la estabilidad postural estática, fuerza en miembros inferiores y core son investigaciones que no se han hecho a profundidad; pero sobre las pocas que hay se ha determinado que el tratamiento con crioterapia, hipoterapia, propiocepción, pliometría y entrenamiento en zonas lipolíticas extensivas puede mejorar la pérdida del equilibrio, debido a una mejora en el tono muscular, aumento del rango del movimiento articular, fortalecimiento de agonistas en relación con los antagonistas y fortalecimiento de glúteos (Giagazoglou, Arabatzi, Dipla y Liga, 2012; Araujo, Martins, Freitas, Camargos y Safons, 2018; Oviedo, Guerra-Balic, Baynard y Javierre, 2014). Se recomienda la utilización de los test de estabilidad postural, ya sean directos o indirectos, para llevar un control constante sobre la pérdida o mejora de esta capacidad en cualquier tipo de club, fundación o tutores que tengan a cargo algún sujeto con DC, SD y A.

\section{Metodología y procedimientos}

\section{Participantes}

El estudio se realizó con un total de 22 participantes con SD, DC y A miembros de la Fundación sin límites enlaces para crecer y servir, ubicada en Bogotá, Colombia, cuya edad promedio es de 28,6 $\pm 4,80$ años, un peso corporal de $68,40 \pm 9,22 \mathrm{~kg}$, talla de 1,65 $\pm 0,09 \mathrm{~m}$ y un índice de masa corporal de 25,28 $\pm 3,25 \mathrm{~kg} / \mathrm{m}^{2}$, quienes no tenían una experiencia previa de entrenamiento específico enfocado a la pliometría, estabilidad dinámica y estática, corrección postural y trabajos específicos de la fuerza explosiva (fases concéntricas y excéntricas). Los evaluados presentaron un grado de actividad física moderado a bajo: ejecutaban tres sesiones de clases a la semana (sesiones de 1 hora) a cargo de una persona no profesional en el campo del entrenamiento, quien les daba clases de danza y expresión corporal. En su mayoría no presentan ningún tipo de acercamiento a la actividad deportiva, excepto dos sujetos que practicaban natación. Por otro lado, los sujetos tenían un historial sobre 
formación musical, coordinación visomanual y visopédica a causa de sesiones intensivas diarias (lunes, martes y jueves) por parte de profesores profesionales a cargo. La población tiene experiencia en la integración motora (en cuanto a la percepción temporal y orientación espacial), debido al desarrollo y participación de estos en eventos de presentación y formación artística-musical. Las características de la población pueden encontrarse en la tabla 1.

Tabla 1. Características básicas antropométricas de los sujetos de investigación (descripción estadística, coeficiente de asimetría, desviación estándar, curtosis e intervalo de confianza del $95 \%, \mathrm{n}=22$ )

\begin{tabular}{|c|c|c|c|c|c|c|c|}
\hline $\begin{array}{l}\text { Características } \\
\text { Antropométricas }\end{array}$ & Mínimo & Máximo & Media & DS & Asimetría & Curtosis & $95 \%$ IC \\
\hline Edad (años) & 19.00 & 35.00 & 28.60 & 4.80 & -0.30 & -1.20 & $26.6-30.6$ \\
\hline Talla (m) & 1.46 & 1.78 & 1.65 & 0.09 & -0.59 & -0.28 & $1.61-1.68$ \\
\hline Masa Corporal (kg) & 48.00 & 85.90 & 68.40 & 9.22 & -0.38 & 0.19 & $64.2-72.2$ \\
\hline $\operatorname{imc}\left(\mathrm{kg} / \mathrm{m}^{2}\right)$ & 18.29 & 31.27 & 25.28 & 3.25 & 0.04 & 0.17 & 23.92-26.64 \\
\hline \multicolumn{8}{|c|}{$\begin{aligned} \text { DS } & =\text { desviación estándar. } \\
\text { IC } & =\text { intervalo de confianza } \\
\text { IMC } & =\text { índice de masa corporal } .\end{aligned}$} \\
\hline
\end{tabular}

Fuente: elaboración propia.

\section{Método}

Se realizó una investigación experimental, en la que se ejecutaron pretest y postest con fines descriptivos e interpretativos.

\section{Procedimientos e instrumentos}

Se ejecutó un estudio experimental con los test de salto vertical (protocolo de Abalakov) y estabilidad corporal (test de Iowa), para poder evaluar su capacidad en el salto vertical y estabilidad estática unipodal, con el fin de evidenciar sus deficiencias en estas capacidades y realizar los mesociclos de entrenamiento basados en métodos de estabilidad estática, dinámica, fuerza explosiva y pliometría. 
Se realizó pretest (Iowa Brace y Abalakov), con el fin de comparar si las sesiones de entrenamiento realizadas durante 11 semanas ( 2 meses y 3 semanas) tenían un impacto en el postest (Iowa Brace y Abalakov). El pretest $\mathrm{y}$ el postest se ejecutaron en superficies niveladas. El pretest fue realizado durante la segunda semana de reconocimiento de la población (en horarios de 8 a. m. a 10 a. m.), mientras que el postest, la última semana de impacto en la comunidad (horarios de 8 a. m. a 10 a. m.). Durante las pruebas de salto (Abalakov) y estabilidad unipodal estática (Iowa Brace), los sujetos no presentaban ningún tipo de lesión a nivel muscular o articular, pero algunos de ellos tenían ciertas distorsiones posturales como la escoliosis e hipercifosis. Por otro lado, los test se realizaron por separado, dando espacio entre uno y otro, con el objetivo de que una prueba no afectará los resultados de la otra (se ejecutaron con dos días de separación entre ellos).

Todas las pruebas físicas se realizaron en el lugar de entrenamiento y formación diaria de los sujetos (Fundación Sin Límites Enlaces para Crecer y Servir), quienes tenían la posibilidad de terminar la prueba por voluntad propia. En cuanto a los protocolos éticos se basó el estudio experimental en el protocolo enunciado por Harris y Frader (2011), la declaración de Helsinki (World Medical Association [WMA], 2017). y las normas vigentes legales en Colombia que regulan la investigación en el país. Cada miembro de la investigación firmó un consentimiento informado previo a la iniciación de las pruebas.

\section{Test de salto vertical, protocolo de Abalakov}

El propósito de la prueba de Abalakov ( $\mathrm{ABK}$ ) es evaluar la capacidad de salto del sujeto y su fuerza potencia (explosiva) en miembros inferiores. Según Martínez (2002) y Díaz (2015), dicho test tiene un porcentaje de validez del $0,75 \%$ en el género masculino y $0,58 \%$ en el género femenino. Para el test se usó un flexómetro de $60 \mathrm{~m}, 364 \mathrm{G} 6 \mathrm{JL}$ Blueline, un pliego de $1 \mathrm{~m} \times 1 \mathrm{~m}$ de cartulina color negra y cal blanca, con el propósito de marcar e indicar la altura de salto vertical de los sujetos con SD, DC y A (figura 1). Los pasos para realizar la prueba se describen a continuación:

Se tomó registro de la talla del sujeto en centímetros. Luego se ubicó al sujeto de forma lateral al pliego de cartulina negra, junto a la pared, con ambos pies extendidos y juntos, el cuerpo erguido y con un brazo sobre la cabeza 
extendido, con las palmas mirando hacia la pared y en contacto con esta, para finalmente tomar la altura máxima del sujeto, con un brazo extendido.

Se ubicó de forma lateral al sujeto cerca a la pared, más o menos a $25 \mathrm{~cm}$ de ella, con el tronco erguido y del lado donde se toma la altura máxima con el brazo extendido (figura 2). Luego se impregnó la punta de los dedos con la cal blanca, se le indica al sujeto que permanezca con los brazos extendidos junto a la cadera, con las piernas a la anchura de los hombros y mirada al frente. A la orden del entrenador, el sujeto ejecuta un balanceo de brazos acompañado de una flexión a $90^{\circ}$ de las piernas, seguido de una fase concéntrica explosiva, en la que se ejecuta un salto vertical lo más alto y potente posible. El individuo debía tocar con el brazo más cercano a la pared y untado de cal la máxima altura de salto sobre la cartulina negra. Se hacen tres intentos, y se registra el mejor de estos (Martínez, 2002).

Figura 1. Materiales utilizados para el test de salto vertical de Abalakov: flexómetro de 60 metros, 364G6JL Blueline, cal blanca y cartulina negra de $1 \mathrm{~m} \times 1 \mathrm{~m}$

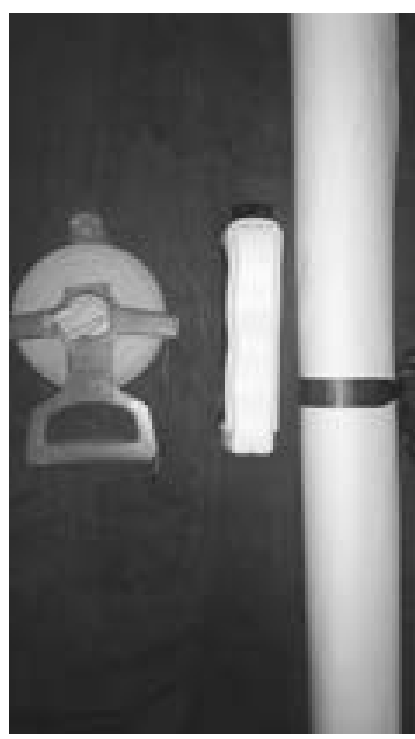

Fuente: elaboración propia. 
Figura 2. Prueba de salto vertical

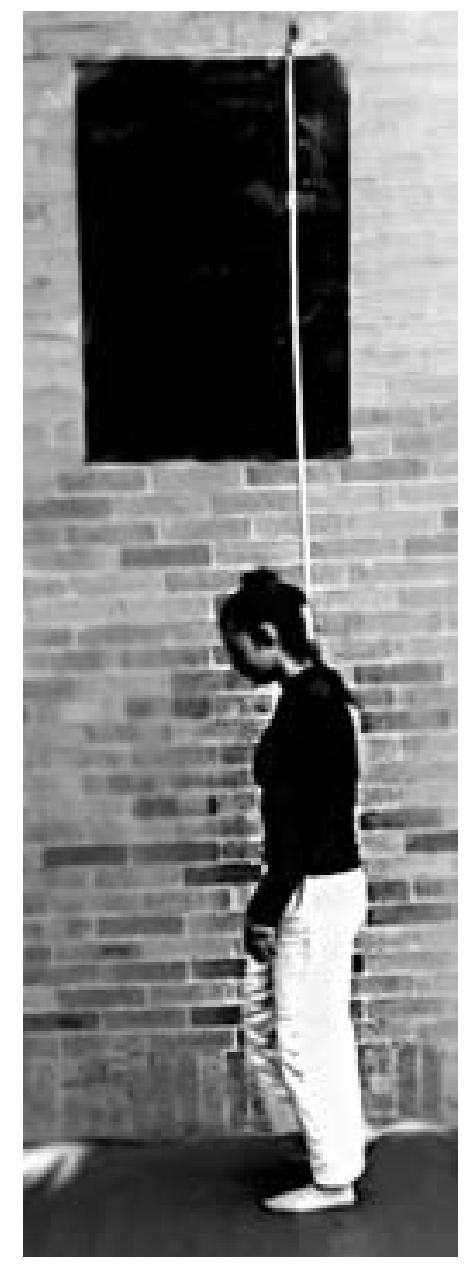

Fuente: elaboración propia.

En la figura 2 se observa la cartulina negra ubicada sobre el muro a $1.80 \mathrm{~m}$ de altura del suelo y un flexómetro pegado a la pared, para identificar la altura máxima del salto. La validez del test se sitúa entre $0,75 \mathrm{~m}$ en hombres y $0,58 \mathrm{~m}$ en mujeres (Martínez, 2002). 
Test de estabilidad estática unipodal, protocolo de lowa Brace

El test de Iowa Brace es una prueba con el propósito de evaluar la estabilidad estática de un individuo. El protocolo descrito por Martínez (2002) es el siguiente (se necesita como material adicional, solo un cronometró -figura 3-):

1. En la postura inicial, el deportista se ubica con las piernas juntas, el tronco derecho y manos juntas al cuerpo.

2. Luego se flexiona el tronco, llevando una pierna hacia atrás en completa extensión, a la vez que los brazos se mantienen en completa extensión, justamente al frente del sujeto.

3. Se mantendrá la posición estática (o lo más quieto posible sin perder el equilibrio) por 30 segundos.

Tabla 2. Rúbrica de puntuación y evaluación para el test de estabilidad estática unipodal de Iowa Brace (Martínez, 2002)

\begin{tabular}{cc}
\hline Puntuación & Características de la evaluación \\
\hline 4 & Se mantiene sin cambiar de posición o moverse \\
3 & Discreta pérdida de equilibrio, sin tocar el suelo \\
2 & Pierde el equilibrio 1 vez o más, tocando el suelo \\
1 & No es capaz de mantener el equilibrio nunca \\
\hline
\end{tabular}

Fuente: elaboración propia.

De acuerdo con la tabla 2, se evaluó a los sujetos ( $\mathrm{n}=22$ ), para luego determinar un promedio de capacidad de estabilidad unipodal estática por el grupo. 
Figura 3. Cronómetro utilizado-Max Electronics MG-506

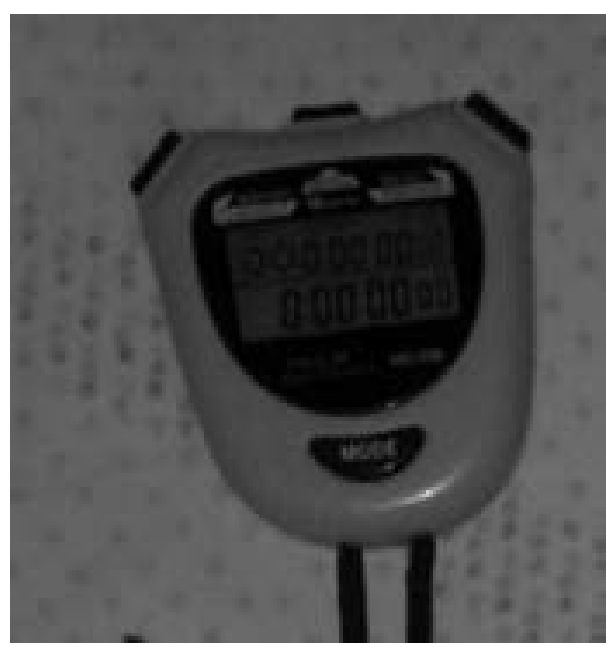

Fuente: elaboración propia.

Figura 4. Posición final del sujeto durante la prueba de Iowa Brace

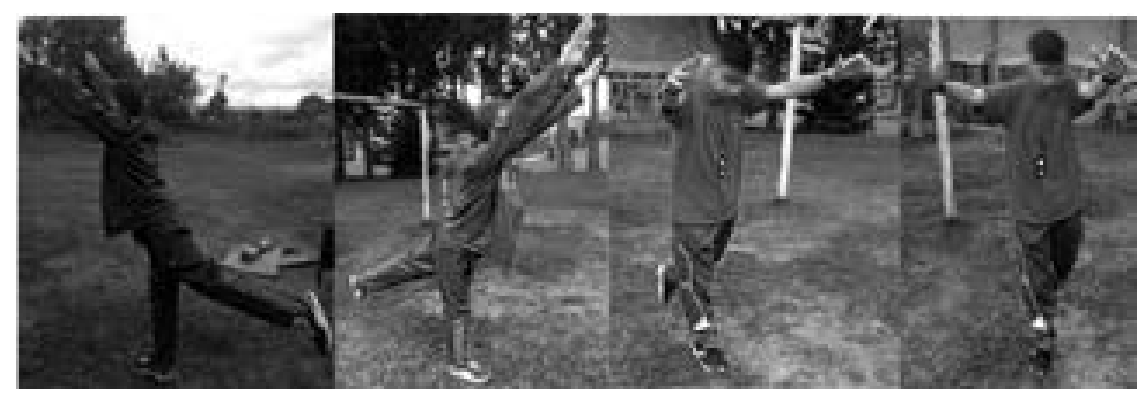

Fuente: elaboración propia.

En la figura 4 se muestra la posición final del sujeto durante la prueba de Iowa Brace, quien se ubica con un solo pie de apoyo, pierna contraria extendida y hombros flexionados justamente en línea con la cabeza. La imagen nos muestra dos tipos de vista de la posición que se debe mantener: lateral (izquierda 
y derecha), diagonal y frontal. El grado de validez del test se sitúa entre 0,85 y 0,95 (Martínez, 2002).

\section{Programa de entrenamiento}

Las sesiones de entrenamiento se llevaron bajo un control, plasmado en un mesociclo (entrenamiento de 2 meses y 3 semanas, realizado 2 veces por semana, con una intensidad por sesión de 2 horas de entrenamiento), de entrenamiento enfocado al trabajo de fuerza explosiva, por medio de métodos pliométricos de bajo impacto y cambios de ritmo en diferentes direcciones (anterior-posterior, medial lateral, izquierda-derecha y diagonales). También se trabajó la estabilidad estática desde métodos propioceptivos, métodos de corrección postural (hábitos posturales al sentarse, caminar y recoger objetos), fortalecimiento de la zona core con trabajos isométricos en fit balls, o sobre colchonetas (ejercicios como planchas supinas, pronas y laterales).

Finalmente, para el fortalecimiento de la capacidad de salto y estabilidad estática, se trabajaron ejercicios de salto vertical (Squat Jump, Counter Movement Jump y Abalakov Jump), y la corrección de patrones básicos (la correcta realización de una sentadilla, tijera, flexión de codos o push ups y las planchas isométricas laterales, supinas y pronas). Los ejercicios mostrados en la tabla 3 se incluyeron durante todas las sesiones de entrenamiento, desde la primera hasta la última, ya como parte del calentamiento, fase central o fase final de la planificación. Los descansos durante las sesiones fueron activos, combinando dichos ejercicios con un trote activo, estiramientos dinámicos o juegos didácticos. 
Tabla 3. Ejercicios que hicieron parte en todas las sesiones de entrenamiento durante la intervención a los sujetos con SD, DC y A
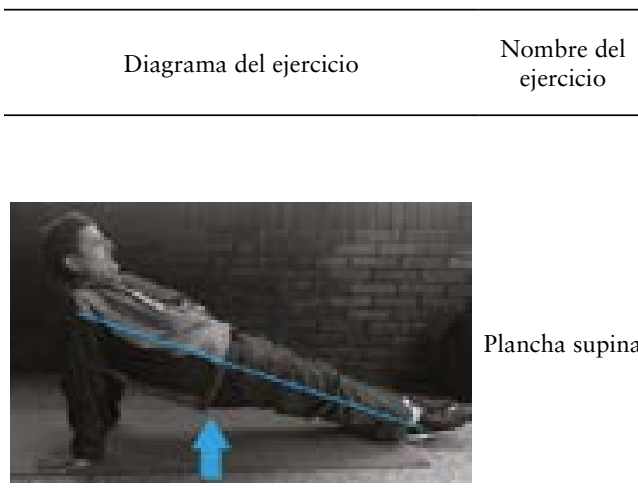
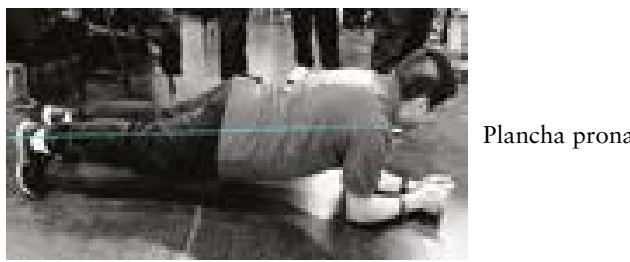

Se realizó boca abajo utilizando los antebrazos de apoyo y la punta de los pies y levantando el tronco con la pelvis en una posición neutral.

cuerpo boca arriba

utilizando como

apoyo las manos y

los pies, levantan-

do el tronco y la pelvis lo más que se pueda.

Nota: mantener el tronco erguido, las piernas extendidas y los brazos en semiflexión.

De forma lateral,
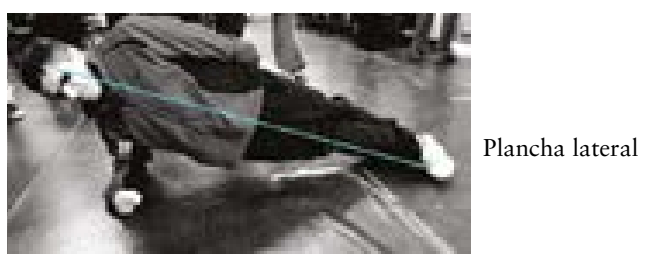
apoyo un antebrazo y un pie, el sujeto se ubica sobre el izquierdo o derecho como apoyo, flexionando el brazo a 90 grados. utilizando como antebrazo del lado

Dosificación

Mes $1 \quad$ Mes 2

Rep:

S1: $2 \times$

30

S2: $2 \times \quad$ S5: $3 \times 45$

$30 \quad$ S6: $3 \times 45$

S3: $3 \times \quad$ S7: $4 \times 1$,

30 .' S8: $4 \times 1$,

S4: $3 \times$

30. Ser:

S5: 1

Ser: S6: 2

S1: $1 \quad$ S7: 3

S2: $1 \quad$ S8: 2

S3: 2

S4: 2

Rep:

S1: $2 \times$

30 "

S2: $2 \times$

30

S3: $3 \times$

30

S4: $3 x$

$30^{\circ}$

Ser:

S1: 1

S2: 1

S3: 2

S4: 2

Rep:

S1: $2 \times$

30

S2: $2 \times$ 30

S3: $3 \times$

30

S4: $3 \times$ 30

Ser:

S1: 1

S2: 1

S3: 2

S4: 2

\section{Rep:}

S5: $3 \times 45$

S6: $3 \times 45$

S7: $4 \times 1$,

S8: $4 \times 1$,

Ser:

S5: 1

S6: 2

S7: 3

S8: 2

Rep: S5: $3 \times 45$

S6: $3 \times 45$.

S7: $4 \times 1$,

S8: $4 \times 1$ '

Ser:

S5: 1

S6: 2

S7: 3

S8: 2 


\begin{tabular}{|c|c|c|c|c|}
\hline \multirow{2}{*}{ Diagrama del ejercicio } & \multirow{2}{*}{$\begin{array}{c}\text { Nombre del } \\
\text { ejercicio }\end{array}$} & \multirow{2}{*}{ Explicación } & \multicolumn{2}{|c|}{ Dosificación } \\
\hline & & & Mes 1 & Mes 2 \\
\hline & Hip thrust & $\begin{array}{l}\text { Se realizó con la } \\
\text { persona boca arriba, } \\
\text { flexionando las } \\
\text { piernas aproxi- } \\
\text { madamente } 90^{\circ} \text { y } \\
\text { levantando la pelvis, } \\
\text { con la ayuda de los } \\
\text { músculos isquio- } \\
\text { tibiales y glúteos. } \\
\text { Retornando de } \\
\text { nuevo la pelvis a la } \\
\text { posición inicial sin } \\
\text { tocar el suelo con } \\
\text { los glúteos. }\end{array}$ & $\begin{array}{l}\text { Rep: } \\
\text { S1: } 8 \\
\text { S2: } 8 \\
\text { S3: } 12 \\
\text { S4: } 12 \\
\text { Ser: } \\
\text { S1: } 2 \\
\text { S2: } 2 \\
\text { S3: } 3 \\
\text { S4: } 3\end{array}$ & $\begin{array}{l}\text { Rep: } \\
\text { S5:12 } \\
\text { S6: } 15 \\
\text { S7: } 20 \\
\text { S8: } 20 \\
\\
\text { Ser: } \\
\text { S5: } 3 \\
\text { S6: } 3 \\
\text { S7: } 3 \\
\text { S8: } 3\end{array}$ \\
\hline 8 & $\begin{array}{l}\text { Sentadilla } \\
\text { isométrica }\end{array}$ & $\begin{array}{l}\text { Utilizando la pared } \\
\text { como apoyo, se rea- } \\
\text { liza una sentadilla } \\
\text { de } 90^{\circ} \text {, mantenien- } \\
\text { do la espalda recta } \\
\text { con los brazos en la } \\
\text { cadera, muslos o al } \\
\text { frente del sujeto. }\end{array}$ & $\begin{array}{c}\text { Rep: } \\
\text { S1: } 2 \times \\
30 * \\
\text { S2: } 2 \times \\
30 * \\
\text { S3: } 3 \times \\
40^{*} \\
\text { S4: } 3 \times \\
40^{*} \\
\\
\text { Ser: } \\
\text { S1: } 1 \\
\text { S2: } 1 \\
\text { S3: } 2 \\
\text { S4: } 2\end{array}$ & $\begin{array}{c}\text { Rep: } \\
\text { S5: } 3 \times 45 \\
\text { S6: } 3 \times 45^{\prime} \\
\text { S7: } 4 \times 1 \\
\text { S8: } 4 \times 1 \text {, } \\
\text { Ser: } \\
\text { S5: } 1 \\
\text { S6: } 2 \\
\text { S7: } 3 \\
\text { S8: } 2\end{array}$ \\
\hline & Squat jump & $\begin{array}{l}\text { Ubicado en senta- } \\
\text { dilla a } 90^{\circ} \text { con los } \\
\text { brazos en la cadera, } \\
\text { el sujeto debía reali- } \\
\text { zar una contracción } \\
\text { concéntrica de las } \\
\text { piernas sin ejecutar } \\
\text { ningún rebote o } \\
\text { acción excéntrica, } \\
\text { para poder saltar } \\
\text { de forma vertical lo } \\
\text { más alto posible. }\end{array}$ & $\begin{array}{l}\text { Rep: } \\
\text { S1: } 4 \\
\text { S2: } 7 \\
\text { S3: } 8 \\
\text { S4: } 8 \\
\\
\text { Ser: } \\
\text { S1: } 2 \\
\text { S2: } 2 \\
\text { S3: } 3 \\
\text { S4: } 3\end{array}$ & $\begin{array}{l}\text { Rep: } \\
\text { S5: } 10 \\
\text { S6: } 10 \\
\text { S7: } 12 \\
\text { S8: } 15 \\
\\
\text { Ser: } \\
\text { S5: } 3 \\
\text { S6: } 4 \\
\text { S7: } 4 \\
\text { S8: } 3\end{array}$ \\
\hline & $\begin{array}{l}\text { CMJ (Coun- } \\
\text { termovement } \\
\text { Jump) }\end{array}$ & $\begin{array}{l}\text { Ubicado de pie, con } \\
\text { el tronco erguido y } \\
\text { las manos en la cin- } \\
\text { tura, se ejecuta una } \\
\text { sentadilla máxima } \\
\text { de } 90^{\circ} \text { de flexión, } \\
\text { para luego de forma } \\
\text { instantánea y ex- } \\
\text { plosiva realizar una } \\
\text { acción concéntrica } \\
\text { de salto vertical lo } \\
\text { más alto posible. }\end{array}$ & $\begin{array}{l}\text { Rep: } \\
\text { S1: } 4 \\
\text { S2: } 7 \\
\text { S3: } 8 \\
\text { S4: } 8 \\
\\
\text { Ser: } \\
\text { S1: } 2 \\
\text { S2: } 2 \\
\text { S3: } 3 \\
\text { S4: } 3\end{array}$ & $\begin{array}{c}\text { Rep: } \\
\text { S5: } 10 \\
\text { S6: } 10 \\
\text { S7: } 12 \\
\text { S8: } 15 \\
\\
\text { Ser: } \\
\text { S5: } 3 \\
\text { S6: } 4 \\
\text { S7: } 4 \\
\text { S8: } 3\end{array}$ \\
\hline
\end{tabular}


Entrenamiento de la pliometría y propiocepción en discapacidad cognitiva, síndrome de Down y autismo

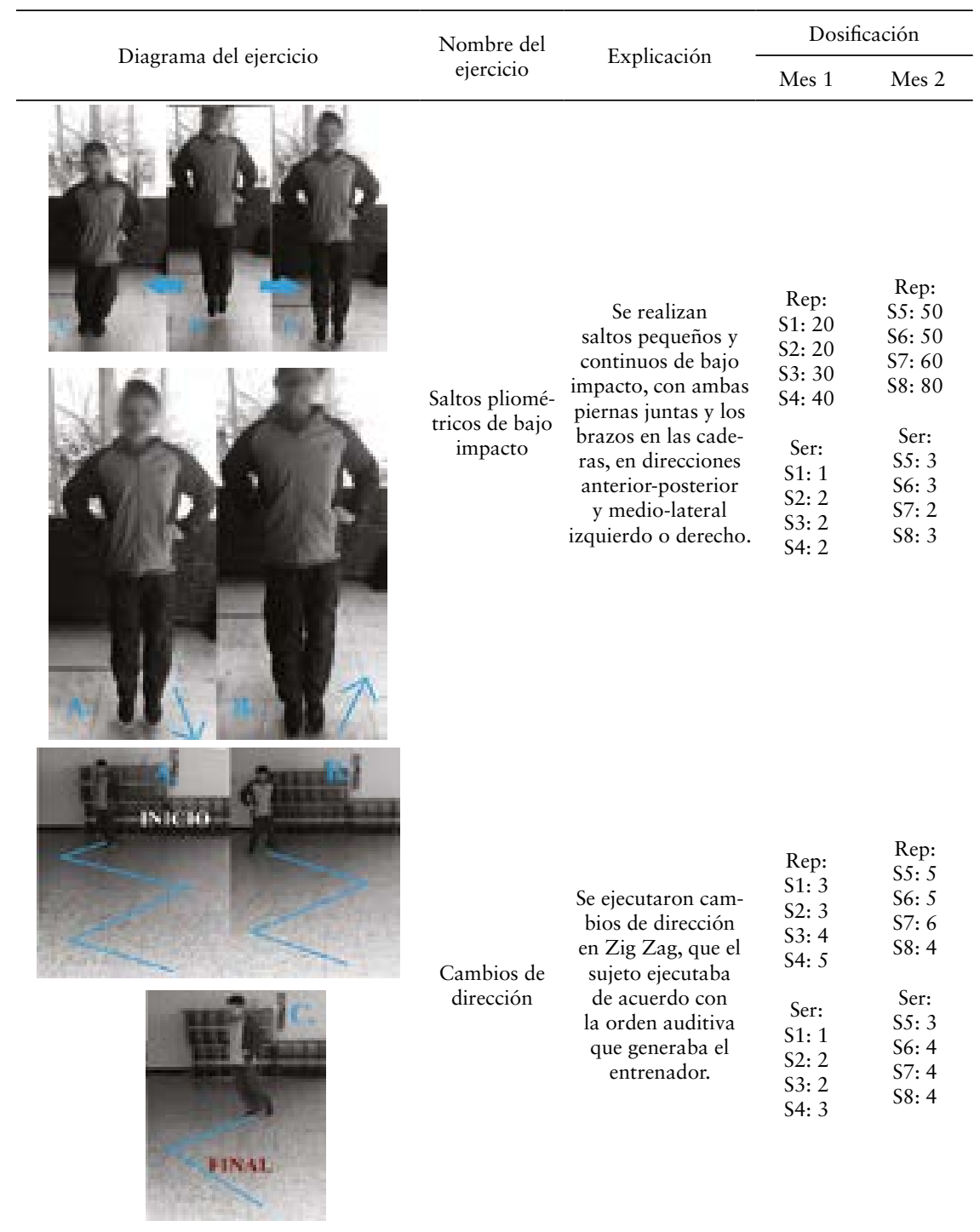




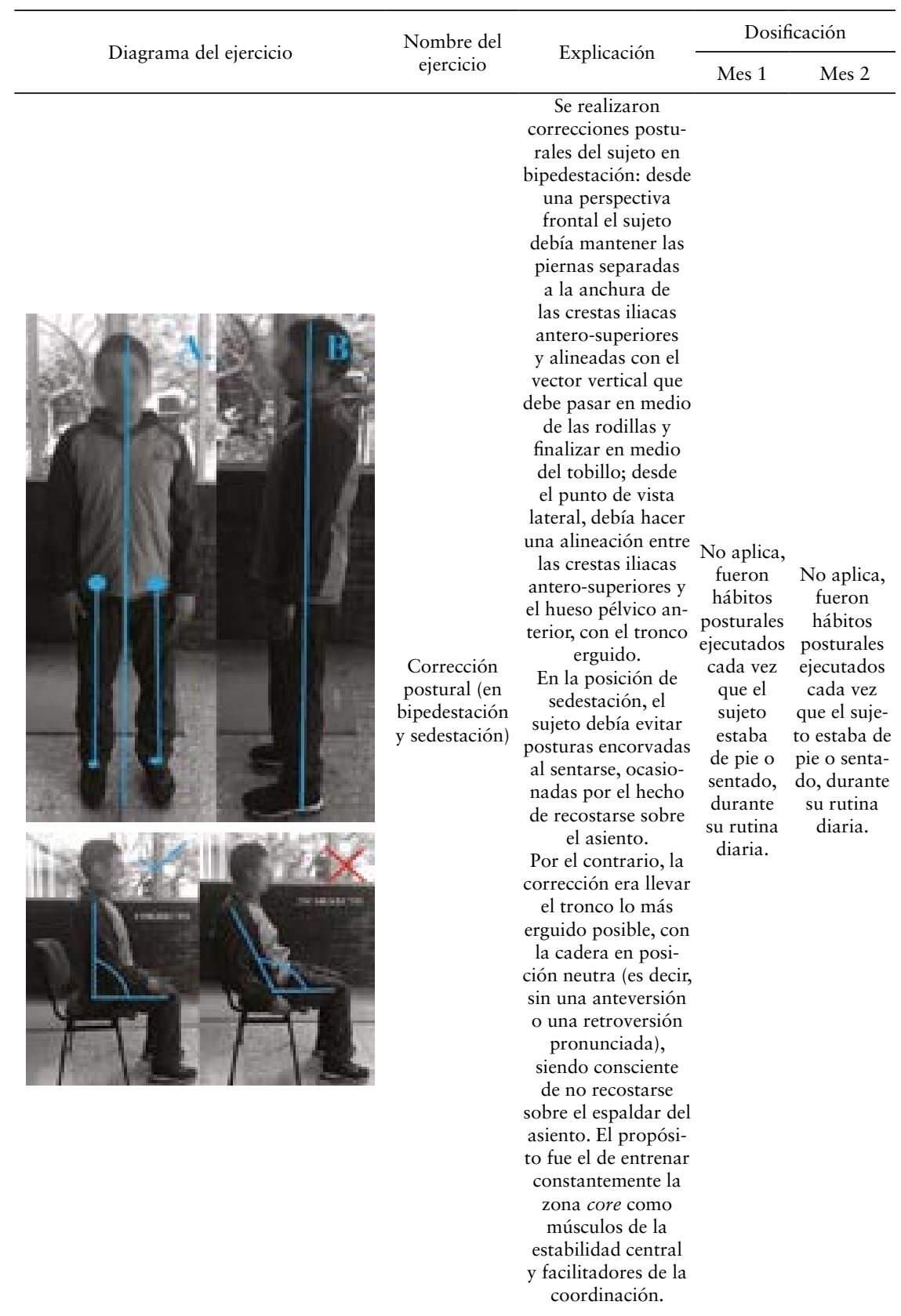




\begin{tabular}{|c|c|c|c|c|}
\hline \multirow{2}{*}{ Diagrama del ejercicio } & \multirow{2}{*}{$\begin{array}{l}\text { Nombre del } \\
\text { ejercicio }\end{array}$} & \multirow{2}{*}{ Explicación } & \multicolumn{2}{|c|}{ Dosificación } \\
\hline & & & Mes 1 & Mes 2 \\
\hline & $\begin{array}{c}\text { Ejercicios de } \\
\text { disociación } \\
\text { de pelvis vs. } \\
\text { miembros } \\
\text { inferiores. }\end{array}$ & $\begin{array}{l}\text { Se realizaron } \\
\text { ejercicios en los } \\
\text { que el sujeto tenía } \\
\text { que colgarse a una } \\
\text { barra por un tiempo } \\
\text { determinado, hun- } \\
\text { diendo las costillas } \\
\text { y manteniendo el } \\
\text { tronco y brazos } \\
\text { completamente } \\
\text { extendidos. Dichos } \\
\text { ejercicios se acom- } \\
\text { pañan de pequeños } \\
\text { balanceos lado a } \\
\text { lado (monkey bars). } \\
\text { Cada balanceo de } \\
\text { izquierda a derecha } \\
\text { es una repetición. } \\
\text { El ejercicio consiste } \\
\text { en ubicarse sentado } \\
\text { sobre los glúteos, } \\
\text { con las piernas } \\
\text { flexionadas, las } \\
\text { manos sobre las } \\
\text { rodillas y brazos } \\
\text { totalmente extendi- } \\
\text { dos. El sujeto debía } \\
\text { llevar el tronco } \\
\text { en flexión hasta } \\
\text { el máximo rango } \\
\text { posible sin ayuda de } \\
\text { la fuerza de brazos } \\
\text { y llegar a movilizar } \\
\text { únicamente la } \\
\text { cadera sobre su } \\
\text { eje transversal sin } \\
\text { modificar o alterar } \\
\text { el movimiento, ya } \\
\text { sea por la ayuda de } \\
\text { los brazos, tronco o } \\
\text { miembros inferiores. }\end{array}$ & $\begin{array}{l}\text { Rep: } \\
\text { S1: } 5 \\
\text { S2: } 8 \\
\text { S3: } 8 \\
\text { S4: } 10 \\
\text { Ser: } \\
\text { S1: } 2 \\
\text { S2: } 3 \\
\text { S3: } 4 \\
\text { S4: } 3\end{array}$ & $\begin{array}{c}\text { Rep: } \\
\text { S5: } 15 \\
\text { S6: } 20 \\
\text { S7: } 20 \\
\text { S8: } 25 \\
\\
\text { Ser: } \\
\text { S5: } 2 \\
\text { S6: } 3 \\
\text { S7: } 4 \\
\text { S8: } 3\end{array}$ \\
\hline
\end{tabular}




\begin{tabular}{|c|c|c|c|c|}
\hline \multirow{2}{*}{ Diagrama del ejercicio } & \multirow{2}{*}{$\begin{array}{l}\text { Nombre del } \\
\text { ejercicio }\end{array}$} & \multirow{2}{*}{ Explicación } & \multicolumn{2}{|c|}{ Dosificación } \\
\hline & & & Mes 1 & Mes 2 \\
\hline & $\begin{array}{l}\text { Activación } \\
\text { del transverso } \\
\text { abdominal } \\
\text { mediante la } \\
\text { activación del } \\
\text { diafragma. }\end{array}$ & $\begin{array}{l}\text { De cubito dorsal so- } \\
\text { bre una colchoneta, } \\
\text { las piernas flexio- } \\
\text { nadas y las manos } \\
\text { sobre las crestas } \\
\text { iliacas anteriores, el } \\
\text { sujeto realizaba una } \\
\text { pequeña flexión del } \\
\text { tronco levantan- } \\
\text { do la cabeza y } \\
\text { hombros del suelo } \\
\text { (sin arquear la zona } \\
\text { lumbar, siempre } \\
\text { debió estar en con- } \\
\text { tacto con el suelo), } \\
\text { para mantener esta } \\
\text { contracción por } \\
\text { unos segundos. Lo } \\
\text { importante allí era } \\
\text { sentir el ascenso } \\
\text { o contracción } \\
\text { del transverso } \\
\text { abdominal con } \\
\text { los dedos índice y } \\
\text { corazón (ejercicio } \\
\text { hipopresivo). }\end{array}$ & $\begin{array}{c}\text { Rep: } \\
\text { S1: } 2 \times \\
30{ }^{*} \\
\text { S2: } 2 \times \\
30^{*} \\
\text { S3: } 3 \times \\
30^{*} \\
\text { S4: } 3 \times \\
30^{\circ .} \\
\text { Ser: } \\
\text { S1: } 1 \\
\text { S2: } 1 \\
\text { S3: } 2 \\
\text { S4: } 2\end{array}$ & $\begin{array}{c}\text { Rep: } \\
\text { S5: } 3 \times 45 \\
\text { S6: } 3 \times 45 \\
\text { S7: } 4 \times 1 \text {, } \\
\text { S8: } 4 \times 1 \text {, } \\
\text { Ser: } \\
\text { S5: } 1 \\
\text { S6: } 2 \\
\text { S7: } 3 \\
\text { S8: } 2\end{array}$ \\
\hline & $\begin{array}{l}\text { Peso muerto } \\
\text { unipodal. }\end{array}$ & $\begin{array}{l}\text { Utilizando el apoyo } \\
\text { unipodal mientras } \\
\text { se levanta el otro } \\
\text { pie y cadera en } \\
\text { extensión hacia la } \\
\text { parte posterior del } \\
\text { cuerpo, mientras } \\
\text { el tronco y sus } \\
\text { brazos se desplazan } \\
\text { perpendicularmente } \\
\text { al pie levantado, } \\
\text { sosteniendo esta } \\
\text { posición el mayor } \\
\text { tiempo posible. } \\
\text { Tener en cuenta } \\
\text { que el tronco debe } \\
\text { estar lo más erguido } \\
\text { posible. }\end{array}$ & $\begin{array}{c}\text { Rep: } \\
\text { S1: } 2 \times \\
30 \\
\text { S2: } 2 \times \\
30 \\
\text { S3: } 3 \times \\
3{ }^{*} \\
\text { S4: } 3 \times \\
30^{*} \\
\\
\text { Ser: } \\
\text { S1: } 1 \\
\text { S2: } 2 \\
\text { S3: } 3 \\
\text { S4: } 3\end{array}$ & $\begin{array}{c}\text { Rep: } \\
\text { S5: } 4 \times 40 \\
\text { S6: } 3 \times 40 \\
\text { S7: } 3 \times 1 \text {, } \\
\text { S8: } 3 \times 1 \text {, } \\
\text { Ser: } \\
\text { S5: } 2 \\
\text { S6: } 3 \\
\text { S7: } 2 \\
\text { S8: } 3\end{array}$ \\
\hline
\end{tabular}

Fuente: elaboración propia. Rep.=repeticiones, Ser= Series, S1: Semana 1, S2: Semana 2, S3: Semana 3, S4: Semana 4, S5: Semana 5, S6: Semana 6, S7: Semana 7, S8: Semana 8, (" = segundos,' minutos). 


\section{Análisis de datos}

Para la toma de datos se utilizó el programa Microsoft Excel Professional Plus 2016 (Microsoft Corporation, Washington, EE. UU.). Se ejecutó un análisis estadístico descriptivo de los resultados; la determinación de un rango (máximo y mínimo), la media (X), la desviación estándar (DS), los índices de asimetría, de curtosis y finalmente los intervalos de confianza (IC) de $95 \%$, para evaluar el comportamiento de las variables y permitir que los baremos se encuentren dentro de un rango de error máximo y mínimo sobre la media. Se determinó la distribución normal de todas las variables numéricas entre todos los pretest y postest con la prueba Shapiro Wilk, donde los datos estuvieron sobre la normal de $(p<0.05)$.

Las adaptaciones y cambios generados por el entrenamiento se evaluaron por medio de la varianza Anova $2 * 2$ (pre y postest), con el fin de saber si había diferencias relevantes (significantes) entre los pretest y postest, validando el impacto del entrenamiento. También se empleó la T de Student de muestras independientes, con el propósito de conocer si habían algunas diferencias entre los pre y posttest de salto vertical de ABK y la estabilidad unipodal de Iowa Brace. Por otro lado, se tomó la magnitud del efecto y el porcentaje de cambio utilizando la $d$ de Cohen (1988) (reconociendo los rangos de cambio donde $d=0.20$ es un efecto bajo, $d=0.50$ es un efecto medio, $d=0.80$ es un efecto alto y una $d=01.30$ es un efecto muy alto (Cohen, 1988). Los resultados del estudio se expresan en valores estadísticos descriptivos de media (X) y desviación estándar (DS).

\section{Resultados y discusión}

En la tabla 4 podemos observar los resultados de los test de Abalakov y de estabilidad unipodal (protocolo de Iowa Brace), pre entreno y post entreno. 
Tabla 4. Resultados de las mediciones de los test de salto vertical y estabilidad unipodal con el protocolo de Abalakov y el test de Iowa Brace, antes y después del programa de entrenamiento

\begin{tabular}{ccccc}
\hline & Pre Entreno & Post Entreno & Tamaño del efecto & \% de cambio \\
\hline Altura ABK $(\mathrm{X} \pm \mathrm{DS})$ & $23.4 \pm 9.1$ & $29 \pm 9 *$ & 0.61 & 23.7 \\
$\mathrm{P}=$ estabilidad-Iowa $(\mathrm{X} \pm \mathrm{DS})$ & $2.1 \pm 0.7$ & $3.2 \pm 0.6^{*}$ & 1.47 & 48.4 \\
\hline
\end{tabular}

Nota: $\mathrm{X}=$ Media, $\mathrm{DS}=$ Desviación Estándar, $\mathrm{ABK}=$ Abalakov, $\mathrm{P}=$ Puntuación del test de 1 a 4 , " Diferencias significativas $p<0.00$.

Fuente: elaboración propia.

La prueba $\mathrm{T}$ de Student para muestras relacionadas refleja una mejora significativa en la altura de salto vertical con el protocolo de ABK $(r=0.95$, ET (error típico) $2.81, p<0.000$ ) y en los test de estabilidad estática unipodal de Iowa Brace $(\mathrm{r}=0.57, \mathrm{ET}=0.60, \mathrm{p}<0.005)$, después de un programa de entrenamiento enfocado a la pliometría y propiocepción. Cabe resaltar que hubo cambios más significativos en la estabilidad unipodal en comparación con la altura de salto vertical, cuya diferencia porcentual de cambio entre los dos test fue de $24.7 \%$ entre ellos (figura 5). Las figuras 6 y 7 resumen el impacto del entrenamiento pliométrico y propioceptivo en la estabilidad unipodal y salto vertical en sujetos con SD, A y DC.

Figura 5. Comparación de pre y postest de Iowa Brace y ABK

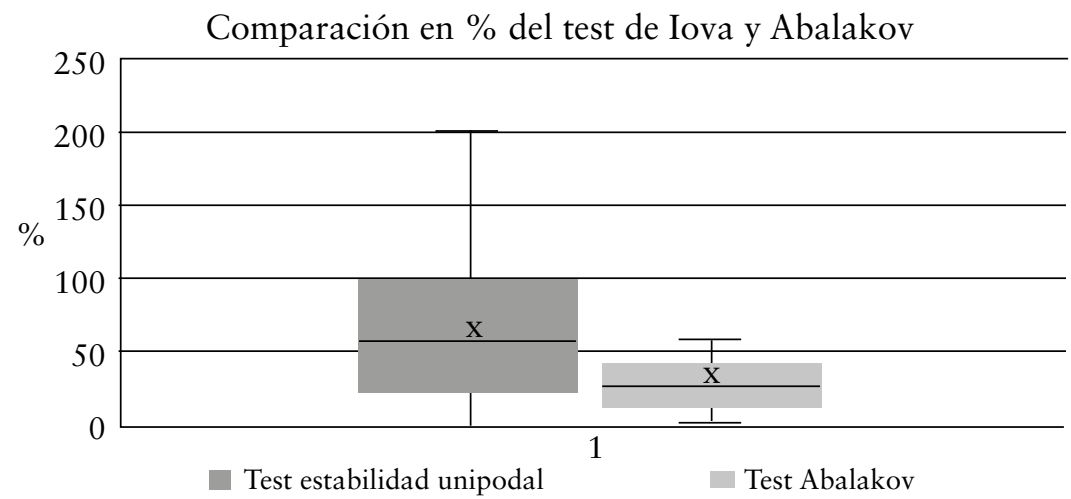

Fuente: elaboración propia. 
Figura 6. Diferencias pretest y postest de estabilidad unipodal bajo el protocolo de Iowa Brace

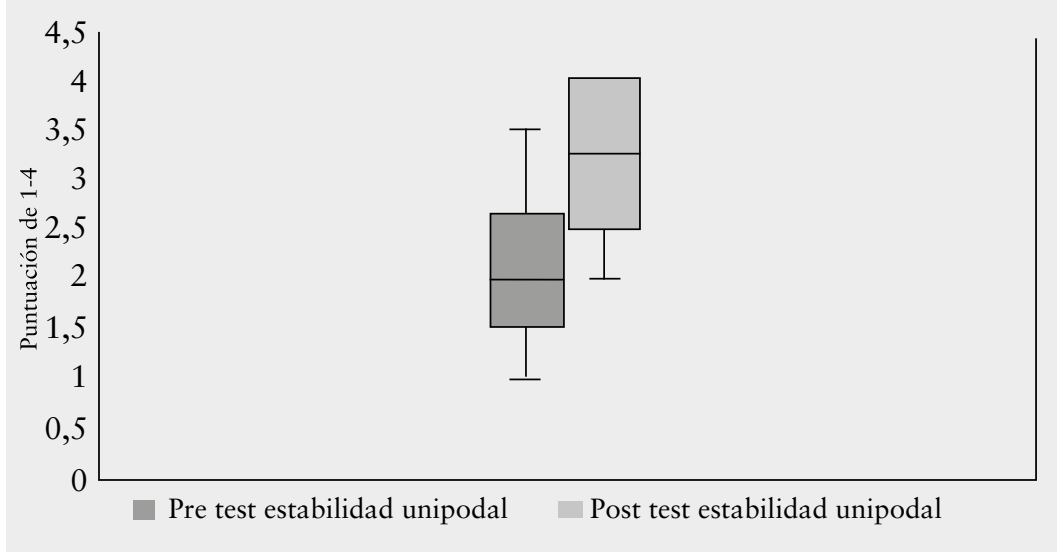

Fuente: elaboración propia.

Figura 7. Diferencias pretest y postest del salto vertical bajo el protocolo de ABK

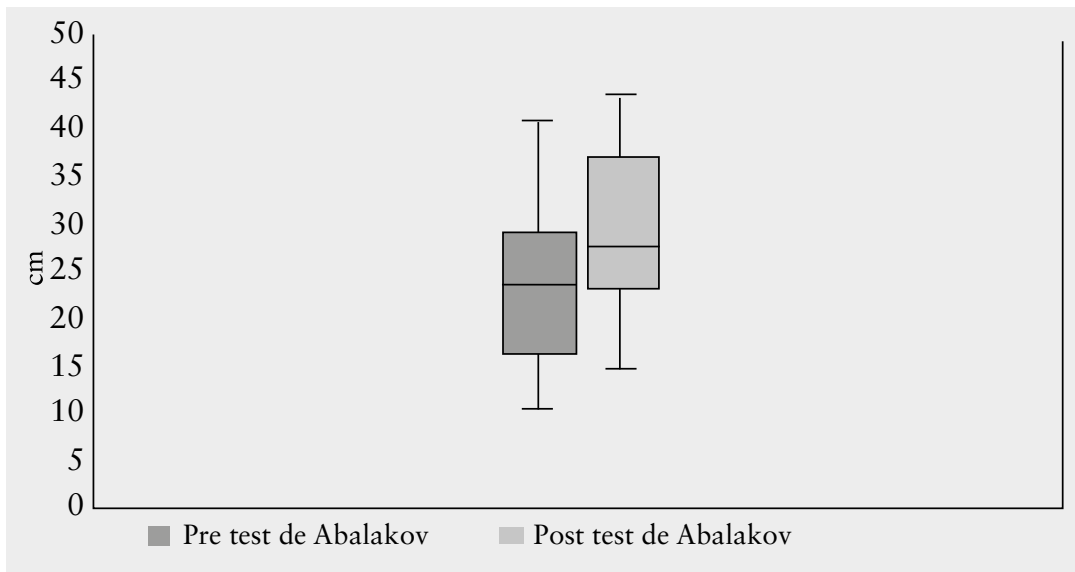

Fuente: elaboración propia. 
Para responder a la pregunta de nuestra investigación durante el desarrollo del artículo, se dio a conocer la caracterización fisiológica, psicológica y motriz, de las personas con DC, SD y A, así como la importancia de la medición continua del salto vertical y la estabilidad estática, con el propósito de dar a conocer la importancia de los test que se evaluaron y su razón lógica en los hábitos posturales, pérdida del equilibrio, hipotonía muscular e hiperlaxitud de segmentos osteomusculares de dicha población.

La intervención realizada generó un cambio en los pre y postest de un $23.7 \%$, a favor del protocolo de salto vertical de ABK, y un cambio de $48.4 \%$ favorable con el protocolo lowa Brace. Investigaciones realizadas por Torres et al. (2019); Giagazoglou et al. (2013) y González, Villarroya, Rodríguez y Casajús (2009) resaltan la importancia del trabajo pliométrico y propioceptivo en la disminución de pérdida de la estabilidad, debido a la corrección de balances y asimetrías, en cuanto a fuerza y a nivel muscular. Por otro lado, Weineck (2005) y Hans y Hans (2005) sugieren que, para mejorar la estabilidad postural y la capacidad de salto vertical, los métodos de entrenamiento se deben enfocar al fortalecimiento de los músculos del core y glúteos.

Según González et al. (2014), Acosta et al. (2018) y Weuve (2004), la estabilidad postural, la poca pérdida del equilibrio, la mejora de los gestos mecánicos (como correr, caminar, saltar, girar, realizar cambios de dirección, entre otros) y la corrección postural o higiene postural se pueden trabajar y mejorar con ejercicios focalizados a fortalecer la zona core (transverso abdominal, cuadrado lumbar, diafragma, suelo pélvico, multífidos, oblicuo interno y externo), y los glúteos (glúteo medio, mayor y menor). Bowman (2019) plantea que, para mejorar la estabilidad postural de un sujeto, se debe disociar las extremidades del cuerpo (tanto las superiores como las inferiores) del tronco; es decir, el rango de movilidad articular de los segmentos glenohumerales y coxofemorales deben ejecutarse libremente y no obstruir cadenas musculares adjuntas en dichas articulaciones, permitiendo la ejecución libre de movimientos y la activación total de la zona core, además de evitar lesiones lumbopélvicas y permitir la mejora del equilibrio del sujeto.

El programa de entrenamiento se basó en las anteriores investigaciones, para validar la importancia del trabajo pliométrico y propioceptivo en la estabilidad postural y capacidad de salto vertical en sujetos con SD, A y DC, para lo cual se realizaron ejercicios como la plancha supina, CMJ, SJ, Saltos pliométricos de bajo impacto, ejercicios de disociación de brazos con tronco 
y de miembros inferiores con la pelvis, cambios de dirección, entre otros ejercicios que permitieron la mejoría significativa del salto vertical y estabilidad unipodal durante los dos meses de intervención.

\section{Conclusión}

Se determina que ambos tipos de entrenamiento, tanto el pliométrico como el propioceptivo, mejoran significativamente la estabilidad estática unipodal y la capacidad de salto vertical (aunque en un porcentaje mayor la estabilidad unipodal) en sujetos con SD, A y DC. De esta manera, se contribuyó a la coordinación y estabilidad de gestos mecánicos cotidianos, como caminar, correr, saltar, girar, cambios de dirección, entre otros, sin llegar a perder fácilmente el equilibrio. Por otro lado, se evidencia un beneficio del programa de entrenamiento en aspectos sociales de interacción con los demás, pero este tema debería ser objetivo de otra investigación más profunda. Se recomienda que, en los entrenamientos enfocados a la mejora progresiva de la estabilidad y fuerza de miembros inferiores para las personas con SD, A y DC, se les dé importancia a los músculos agonistas y antagonistas de los miembros inferiores, al fortalecimiento de glúteos y core, y a la corrección postural en sedestación y bipedestación.

\section{Referencias}

American Association of Intellectual Discapacities or from Development (AAIDD). (2011). Discapacidadintelectual.Definición, clasificaciónysistemas deapoyosocial. Madrid: Alianza. Recuperado de https://blogs.ucv.es/postgradopsocologia/2017/12/15/ discapacidad-intelectual-definicion-clasificacion-y-sistemas-de-apoyo-social/

Acosta, E. (2015). Programa de entrenamiento cognitivo de la función ejecutiva en el componente de planeación en adultos del centro de entrenamiento para discapacitados mentales EDISME, de la Sociedad de San Vicente de Paúl de Medellin. Recuperado de: http://bibliotecadigital.usbcali.edu.co:8080/bitstream/10819/2464/1/Programa_Entrenamiento_Cognitivo_Acosta_2015.pdf

Acosta, A., Burgos, D, Hoyos, E., Lilines, T, De la Torre, R. y López, L. (2019). Diseño e Implementación de una Plataforma web para mejorar la organización de los planes de entrenamiento y alimentación de los deportistas de Taekwondo. 
Revista Investigación y Desarrollo en TIC, 10(1), 43-50. Recuperado de http:// revistas.unisimon.edu.co/index.php/identic/article/view/3489

Almeida, G., Narconi, N., Tortoza, C., Ferreira, S., Gotlieb, G. y Corcos, D. (2000). Sensorimotor deficit in down syndrome. Implications for facilitating motor performance. En D. Weeks, R. Chua y D. Elliott (Eds.), Perceptual-Motor Behavior in Down Syndrome (pp. 603-640). Recuperado de https://books.google.es/boo ks?hl=en\&lr=\&id=gZ9JWYumJHwC\&oi=fnd\&pg=PA151\&dq=Almeida,+G . ,+Narconi,+N.,+Tortoza,+C.,+Ferreira, + S.,+Gotlieb,+G.,+\%26+Corcos,+D.+( 2000).+Sensoriomotor+Deficit+in+Down+Syndrome.+Implications+for+facilit ating+motor+performance.+Human+Kinetics,+603-640.\&ots=L28kLXMQQ o\&sig=CVi4FmOk8486iKU56w-kGQBuNk8\#v=onepage\&q\&f=false

Alonso, D. (2018). Desarrollo de las habilidades motrices de las personas con discapacidad intelectual a través del proceso cognitivo. ArtsEduca, 19, 225-244. DOI: https://doi.org/10.6035/artseduca.2018.19.10

Araujo, T., Martins, W, Freitas, M, Camargos, E. y Safons, M. (2018). An exploration of equine-assisted therapy to improve balance, functional capacity, and cognition in older adults with Alzheimer disease. Journal of Geriatric Physical Therapy, 42(3), 60-75. DoI: https://doi.org/10.1519/jpt.0000000000000167

Bauman, M. y Kemper, T. L. (1985). Histoanatomic observations of the brain in early infantile autism. Neurology, 35(6), 866-874. DoI: https://doi.org/10.1212/ WNL.35.6.866

Berruezo, P. (1996). La psicomotricidad en España: de un pasado de incomprensión a un futuro de esperanza. Psicomotricidad, Revista de Estudios y Experiencias, $53,57-64$

Bowman, K. (2019). Diastasis recti. Propio Metrics. Recuperado de http://propriometricspress.com/diastasis-recti/

Block, M., Angelo, A., Christoph, S., Stefan, S., Jürgen, V., Patricia, B., ... Helmut, K. (1999). The pacing therapies for congestive heart failure (PATH-CHF) study: rationale, design, and endpoints of a prospective randomized multicenter study. The American Journal of Cardiology, 83(5, Suppl. 2), 130-135. DOI: https://doi.org/10.1016/S0002-9149(98)01014-5

Chávez, R. y Delgado, C. (2009). La danza y su influencia en el desarrollo de la psicomotricidad en los niños/as con discapacidad intelectual del instituto de educación especial "Angélica Flores Zambrano” (tesis de grado). Universidad Laica Eloy Alfaro de Manabí, Manta, Ecuador. 
Cossio, M., Vidal, R., Lagos, J. y Gómez, R. (2015). Perfil antropométrico en función del estado nutricional de niños con discapacidad intelectual. Revista Chilena de Pediatría, 86(1), 18-24. DoI: https://doi.org/10.1016/j.rchipe.2015.04.004

Cohen, J. (1988). Statistical power analysis for the behavioral sciences. New York: Lawrence Earlbaum Associates. Recuperado de http://www.utstat.toronto. edu/ brunner/oldclass/378f16/readings/CohenPower.pdf

Díaz, F, y Francisco, J. (2015). Aspectos físicos y fisiológicos determinantes en brazilian jiu-jitsu, y la utilización de la cafeína como ayuda ergogénica (tesis doctoral). Castilla, España. Recuperado de http://hdl.handle.net/10578/8652

Eberhard, D. A. y Steiner, L. E. (1997). Histopathology of arteriovenous malformations after gamma knife radiosurgery. Journal of Neurosurgery, 87(3), 352357. DOI: https://doi.org/10.3171/jns.1997.87.3.0352

Fernández, P. (2000). La afectividad colectiva. Ciudad de México: Taurus.

Finkelstein, A., Nickel, T., Barnes, T. y Suma, E. (2010). Astrojumper: designing a virtual reality exergame to motivate children with autism to exercise. IEEE virtual reality conference (VR), Waltham, Ma, 267-268. DOI: https://doi. org/10.1109/vr.2010.5444770

Flood, L., Korol, S., Ekselius, L., Birnir, B. y Jin, Z. (2019). Interferon- $\gamma$ potentiates GABAA receptor-mediated inhibitory currents in rat hippocampal CA1 pyramidal neurons. Journal of Neuroimmunology, 337, 577050. DoI: https://doi. org/10.1016/j.jneuroim.2019.577050

Giagazoglou, P., Arabatzi, F., Dipla, K. y Liga, M. (2012). Effect of a hippotherapy intervention program on static balance and strength in adolescents with Intellectual Disabilities. Research Development Disability, 13(6), 2265-2270. DOI: https://doi.org/10.1016/j.ridd.2012.07.004

Giagazoglou, P., Kokaridas, D., Sidiropoulou, M., Patsiaouras, A. y Karra. (2013). Effects of a trampoline exercise intervention on motor performance and balance ability of children with Intellectual Disabilities. Research in Developmental Disabilities, 34(9), 2701-2707. DoI: https://doi.org/10.1016/j. ridd.2013.05.034

González, A., A. Gómez, C., A. Matute, L., A. Gómez, Brutonad, G., Vicente, A. y Casajús, J. A. (2014). Effects of a circuit training including plyometric jumps on cardiorespiratory fitness of children and adolescents with Down Syndrome. International Medical Review on Down Syndrome, 18(3), 35-42. DoI: https:// doi.org/10.1016/s2171-9748(14)70053-4 
González-Agüero, A., Villarroya, M., Vicente-Rodríguez, G. y Casajús, J. A. (2009). Masa muscular, fuerza isométrica y dinámica en las extremidades inferiores de niños y adolescentes con síndrome de Down. Biomecánica, 17(2), 46-51. Recuperado de https://upcommons.upc.edu/handle/2099/11975

Hans, G. y Hans, J. (2005). Entrenamiento médico en rehabilitación. Barcelona: Paidotribo.

Harris, R. y Frader, J. (2011). Ethical issues in the treatment of pediatric patients with disorders of sex development. In D. Diekema, M. Mercurio y M. Adam (Eds.), Clinical Ethics in Pediatrics: A Case-Based Textbook (pp. 160165). Cambridge: Cambridge University Press. doi: https://doi.org/10.1017/ CBO9780511740336.029

Hervás, A. (2016). Un autismo, varios autismos. Variabilidad fenotípica en los trastornos del espectro autista. Revista de Neurología, 62(Supl. 1), S9-S14. DoI: https://doi.org/10.33588/rn.62S01.2016068

Hernández, M. (2018). Influencia de un programa de entrenamiento sensoriomotor sobre el equilibrio estático en nadadores con síndrome de Down y discapacidad intelectual (Tesis Doctoral). Universidad Nacional de Costa Rica. Recuperado de: https://repositorio.una.ac.cr/bitstream/handle/11056/15012/ Tesis\%209786.pdf? sequence $=1$ \&isAllowed $=y$

Hoz, V. (1996). Personalización en la educación física. Madrid. Rialp.

Lang, R., Koegel, L. K., Ashbaugh, K., Regester, A., Ence, W. y Smith, W. (2010). Physical exercise and individuals with autism spectrum disorders: a systematic review. Research in Autism Spectrum Disorders, 4(4), 565-576. Recuperado de https://education.ucsb.edu/sites/default/files/autism_center/images/Lang \%2C\%20Koegel\%2C\%20Ashbaugh\%2C\%20Regester\%2C\%20 Ence \%2C\%20Smith\%20\%282010\%29\%20Physical\%20xercise \% 20 and \%20individuals\%20with\%20ASD\%20a\%20systematic\%20review.pdf

Laudan, B. y Jahromi, A. G. (2008). Emotional competence in children with Down Syndrome: negativity and regulation. American Journal on Mental Retardation, 113(1), 32-43. DoI: https://doi.org/10.1352/0895-8017(2008)11 $3[32:$ ecicwd]2.0.co;2

Llasera, E. (1995). Proposta de descobriment $i$ adaptació al medi aquátic per alumnes amb necesitats educatives especials. Lleida: Organització del IIn. Congrés del'Educació Física i l'Esport. INEF Catalunya.

López, B. (2019). Discapacidad intelectual (DI): ¿Qué es?, diagnóstico, causas, tipos y consejos. CogniFit Salud, Cerebro y Neurociencia. Recuperado de https:// Blog.Cognifit.Com/Es/Discapacidad-Intelectual/ 
López, D., Bruña, R., Garcés, P., Martín, B., Walter, S., Delgado, M. L., ... Maestú, F. (2017). Functional Connectivity Disruption in Subjective Cognitive Decline and Mild Cognitive Impairment: A Common Pattern of Alterations. Frontiers in Aging Neuroscience, 9, 109. DoI: https://doi.org/10.3389/fnagi.2017.00109

López, M. y Sanjuan, E. (2002). Alumnos con deficiencia psíquica. Aspectos a tener en cuenta en las clases de educación física. Revista Internacional de Medicina y Ciencias de la Actividad Física y el Deporte, 2(8), 290-297. Recuperado de http://cdeporte.rediris.es/revista/revista8/deficiencia.htm

Martínez, E. (2002). Pruebas de aptitud física. Barcelona: Paidotribo.

Mateer, C. (2003). introducción a la rehabilitación cognitiva. Avances en Psicología Clinica Latinoamericana, 21, 11-20. Recuperado de http://www.neuropsicologia.com.ar/pdf/c_mateer_introduccion_a_la_rehabilitacion_cognitiva.pdf

McConachie, H., Parr, J. R., Glod, M., Hanratty, J., Livingstone, N., Oono, I. P., ... Williams, K. (2015). «Systematic review of tools to measure outcomes for young children with autism spectrum disorder». Health Technol Assess, 19(41). DoI: http://doi.org/10.3310/hta19410

Mendoza, I. (2017). Programa de actividades físico-recreativas para desarrollar habilidades motrices en personas con discapacidad intelectual. Revista Cubana de Investigaciones Biomédicas, 36(1), 1-13. Recuperado de http://scielo.sld.cu/ pdf/ibi/v36n1/ibi08117.pdf

Mormino, E. C., Betensky, R. A., Hedden, T., Aaron, P., Rebecca, E., ... Reisa, A. (2014). Synergistic Effect of $\beta$-Amyloid and Neurodegeneration on Cognitive Decline in Clinically Normal Individuals. JAMA Neurology, 71(11), 13791385. DOI: https://doi.org/10.1001/jamaneurol.2014.2031

Muñoz, J. (2005). Guía médica y neuropsicológica del autismo. Barcelona: Fundación Autismo Mas Casadevall.

Oviedo, G. R., Guerra-Balic, M., Baynard, T. y Javierre, C. (2014). Effects of aerobic, resistance and balance training in adults with Intellectual Disabilities. Research in Developmental Disabilities, 35, 2624-2634. DoI: https://doi. org/10.1016/j.ridd.2014.06.025

Sánchez, B. (1986). Didáctica de la educación física y el deporte. Madrid: Editorial Gymnos.

Sowa, M. y Meulenbroek, R. (2012). Effects of physical exercise on Autism spectrum disorders: a meta-analysis. Research in Autism Spectrum Disorders, 6(1), 46-57. http://dx.doi.org/10.1016/j.rasd.2011.09.001

Tajima, A., Yokoi, T., Ariga, M., Ito, T., Kaneshiro, E., ... Eto, H. (2009). Clinical and genetic study of Japanese patients with type 3 Gaucher disease. Molecular 
Genetics and Metabolism, 97(4), 272-277. DoI: https://doi.org/10.1016/j. ymgme.2009.05.001

Torres, G., Farías, V., Espoz, L. y Álvarez, A. (2019). Marcadores antropométricos de riesgo cardiovascular y diferentes manifestaciones de la fuerza en adolescentes y adultos chilenos con discapacidad intelectual moderada. Feafys-Trances, 11(3), 515-534. Recuperado de http://shorturl.at/syILQ

Villa, J.y García, L. (2005). Tests de salto vertical (I), Aspectos Funcionales. Rendimiento Deportivo, 6, 1-14. Recuperado de http://hdl.handle.net/10612/9459

Webbers, A., Virji-Babul, N., Edwards, R. y Lesperance, M. (2004). Stiffness and postural stability in adults with Down Syndrome. Experimental Brain Research, 155(4), 450-454. DoI: https://doi.org/10.1007/s00221-003-1743-7

Wehmeyer, M., Kelchner, K. y Richards, S. (1996). Principales características de la conducta autodeterminada de las personas con retraso mental. Siglo Cero, 27(6), 17-24. Recuperado de https://sid.usal.es/4045/8-2-6 Weineck, J. (2005). Entrenamiento Total. Baligen, Alemania: Paidotribo.

Weineck, J. (2005). Entrenamiento Total. Baligen: Paidotribo.

Weuve, J. (2004). Physical activity including walking, and cognitive function in older women. Jama, 292(12), 1454-1461. DoI: https://doi.org/10.1001/ jama.292.12.1454

World Medical Association (wMA). (2017). Declaración de Helsinki de la AMM - Principios Éticos Para Las Investigaciones Médicas En Seres Humanos. Recuperado de https://www.wma.net/es/policies-post/declaracion-de-helsinkide-la-amm-principios-eticos-para-las-investigaciones-medicas-en-seres-humanos/ 